\title{
The new large database of the Russian bottom trawl surveys in the Far Eastern Seas and the North Pacific Ocean in 1977-2010
}

\author{
Igor V. Volvenko \\ Regional Data Center, Pacific Research Fisheries Center (TINRO-Center), Vladivostok, Russia
}

Email address:

volvenko@tinro.ru

To cite this article:

Igor V. Volvenko. The New Large Database of the Russian Bottom Trawl Surveys in the Far Eastern Seas and the North Pacific Ocean in 1977-2010. International Journal of Environmental Monitoring and Analysis. Vol. 2, No. 6, 2014, pp. 302-312.

doi: $10.11648 /$ j.ijema.20140206.12

\begin{abstract}
The new large database (DB) is considered: the history of its development, sources and the volume of the information contained therein, the first experience of operating it and its prospects; the advantages and disadvantages of this DB are discussed; its role in applied (bioresource) and fundamental researches is highlighted; the DB role in the context of the Concept of information support of the fisheries researches of the Far Eastern seas of Russia and the Comprehensive program of environmental safety of Russia is pointed out, as well as the necessity to continue works on its regular updating and filling with the up-to-date data.
\end{abstract}

Keywords: Bottom Macrofauna, Aquatic Bioresources, Trawl Evaluation of Abundance, Pacific Ocean, Bering Sea, Database, Sea of Okhotsk, Japan/East Sea

\section{Introduction}

To continue the implementation of the Concept of the information support of the fisheries researches of the Far Eastern seas of Russia [1] and the Comprehensive program of environmental safety of the Far Eastern seas [2] in accordance with the Complex program of the fisheries researches in the Far Eastern basin [3] after introducing a large database (DB) of pelagic trawl surveys conducted in the Northern part of the Pacific Ocean and adjacent seas [4], TINRO-Center began to develop the similar DB of bottom trawl surveys. It is aimed at being the information source on the benthic ${ }^{1}$ aquatic bioresources (ABR) (these are: pollock, cod, saffron cod, halibut, flounder, greenling, grenadier and other valuable demersal $^{2}$ fish, as well as crabs, shrimps, squids, bivalve and gastropod mollusks, sea urchins, and other commercial invertebrates) and their biotic environment (other components of bottom biocenotic assemblages) for the main fishery basin of Russia. It is known (see, for instance [5-10]) that the Far Eastern seas and adjacent waters of the Pacific Ocean contain the major part of the present-day resource base of the native

\footnotetext{
${ }^{1}$ Benthal-(Greek Benthos - depth), the bottom with the adjacent layer of water as the habitat of organisms.

${ }^{2}$ Demersal - (Latin Demersus - down movement, submersion), something which can be found on the bottom or near it.
}

fishing. According to "Fish News" (http://fishnews.ru/news/22709), the total catch of ABR along Russia reached $4,135 \mathrm{mln}$ tons in 2013. About 2,805 mln tons, which is almost $70 \%$ of the total amount, were caught in the Far East of the country. There are reasons $[7,11]$ to consider that such predominant fishery value of the Far Eastern waters for Russia will remain for the whole foreseen future.

The development of the DB, which is the main theme of the paper, is connected with the implementation of the plan of TINRO-Center researches, approved by the Russian Federal Fisheries Agency. Among the main applied tasks of the institute is the monitoring and forecasting the state of the raw materials base of the native fishing, but all evaluations and forecasts, both model and expert ones, are always based on a particular amount of data - actual observations of the natural phenomena and processes. However, there is usually a rule: the more available data, the more accurate the forecast. For instance, to make a statistical analysis of the cyclical fluctuations in populations there must be time series of observations at least 2 times longer than the duration of one cycle (see e.g. [12]). Figuratively speaking, the initial data are the cornerstones, which are the basis for building the conclusions about the present-day status of the bioresources and their future status forecasting, as well as estimating TLP, SM and other parameters of environmental management [13].

The important peculiarity of the new DB is that within the framework of its development there was the target: to bring 
together not only the maximum volume of the cruise information or the longest series of observations of the single abundant and commercial species, but only those data, which contain complete information on all representatives of the trawl macrofauna ${ }^{3}$ of the bottom biocenotic assemblages. The presence of these data is the indispensable condition of rational use of bioresources and their management on the ecosystem basis [11,14-16], because "the populations of commercial objects do not live in isolation, but as communities (biocenosis). Biocenological background for them is also the habitat, as well as the hydrological regime. One should know it to understand and forecast the changes in the state of bioresources as a whole and the raw materials base of the fishing in particular" ([17], p. 234). Figuratively speaking, "even detailed autecological ${ }^{4}$ understanding of the ecology of commercial objects is only the visible top of the iceberg; however, its major mass stays invisible as it is under the water. But particularly the impact of the streams on it and not the winds on the top of it, defines the path of the iceberg. This underwater part represents the very biocenosis and ecosystems, the main parts of which are the commercial hydrobionts" ([11], p. 6).

Unfortunately, a significant part of the data accumulated by TINRO-Center was hardly suitable or completely unsuitable for the ecosystem or biocenological ${ }^{5}$ researches, which require strict quantitative results, because the commercial-object (aut- and/or demecological ${ }^{6}$ ) approach has been absolutely predominant for many years in collecting and processing the materials of the exploration, search and fishing cruises, and even completely scientific surveys, in accordance with the principles of monospecific fishing [18-20]. The programs of the scientific cruises were developed under the study of single species and groups of commercial objects that is why the quantitative information on other (even commercial) species, as a rule, did not accumulate. Most of hydrobionts the so-called by-catch - in connection with the apparent usefulness, lack of available field identification guides and lack of qualified specialists were defined only to genus or family. Frequently, if they were noted in the trawl cards "Fig. 1 ", they would not be calculated, weighted and measured.

The described situation changed by the end of the $1970^{\mathrm{s}}$ in connection with the development of the ecosystem approach to studying of biological resources within TINRO [5,11,2125], which presupposed the accumulation and analysis of the data on all animal groups, emphasizing the interrelationships between them, the role of the climate and hydrological regime for the fluctuations in their numbers. Particularly in the comprehensive expeditions, basically under the flag of this direction for the last decades of the last century and the first of the present-days one, very extensive qualitative information was collected. Its compilation and interpretation is impossible without organizing it into the form relevant for the analysis by developing a new DB.

\footnotetext{
3 Actually, these are all animals exploited by the bottom trawl equipped in the cod end with the fine-meshed (10-12-mm) insert.

4 Autecology - individual ecology.

5 Biocenology or synecology - the ecological study of communities, assemblages and other multispecific groups of organisms.

${ }^{6}$ Demecology - the ecology of populations.
}

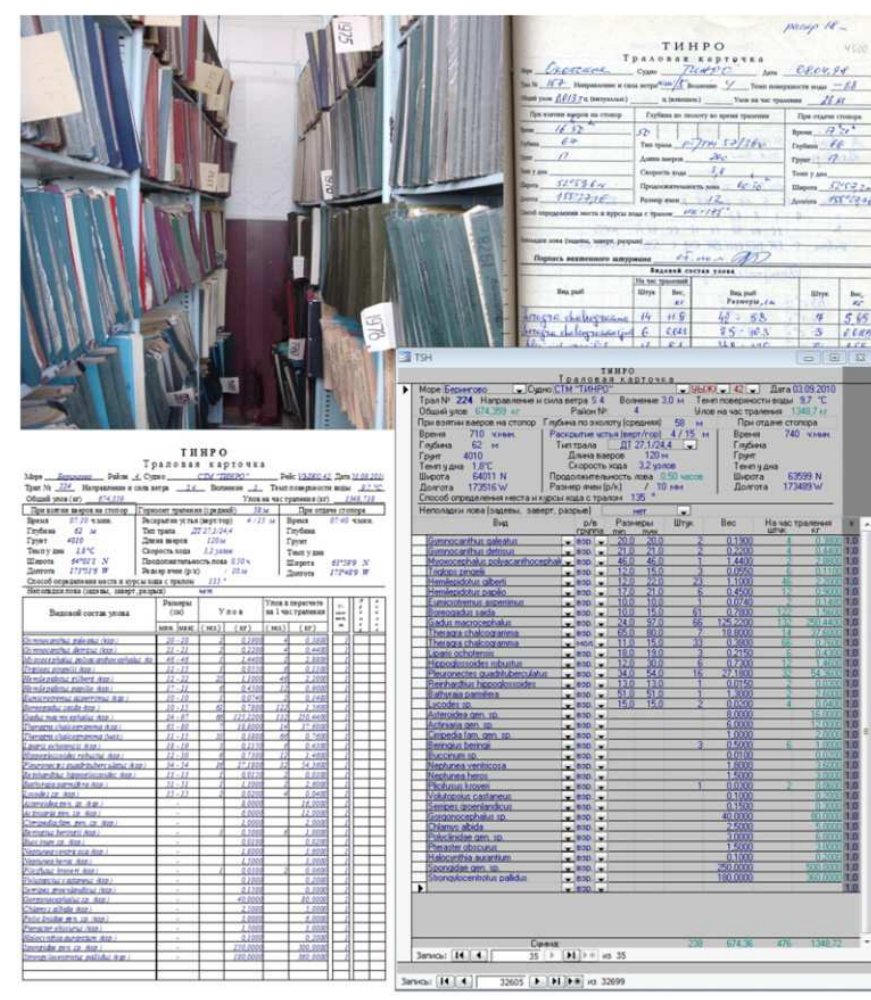

Figure 1. Trawl cards, from which the initial information for the database was taken, are the documents filled by navigators and ichthyologists for each scientific or commercial trawling. Top left-a fragment of a photo of two of the plurality of shelves with binders of the trawl cards in the archive of TINRO-Center. Above right - the scanned image of the front side of trawl card filled "by hand" in the pre-computer era of researches. Bottom left - modern card - printing out of "ARM-t" (Automated Work Place for Trawling Research). Bottom right - one of possible representations of the same card in the computer database

\section{Materials and Methods}

The initial materials for the new DB were the digitized data from the trawl cards "Fig. 1" filled in during the numerous bottom trawl surveys carried out with the participation of the TINRO employers. These data were taken from another large DB "Marine biology" (state registration No. 0220006765), the constant replenishment of which is conducted under the results of all present-day cruises, as well as due to the digitization of historical materials collected in the pre-computer era of the marine researches - by means of the manual data entry, read from the paper sources preserved in the archive of the initial information since $1950^{\mathrm{s}}$ [13]. By the beginning of work on the new DB, the Marine biology DB contained the data of almost 140 thousand trawl stations. More than a half of them are the bottom ones.

The preliminary painstaking work in the archive with the volumes of trawl cards and on computers with the digitized data allowed to choose those cruises where all fish from the catches were investigated and recorded, as well as exclude the trawling: 1) accident-related, 2) technical or setup, 3) purely commercially fishing, 4) sighting trawling on echo records, 5) lasted more than 3.5 hours, or no more than 5 minutes (if in the latter case the trawl comes on board without a catch) 6) performed with a speed of less than 2 knots. It turned out that these requirements are met by less than $50 \%$ of the bottom trawl stations, which materials are contained in the Marine 
Biology DB. Their distribution in the water area is shown on "Fig. 2".

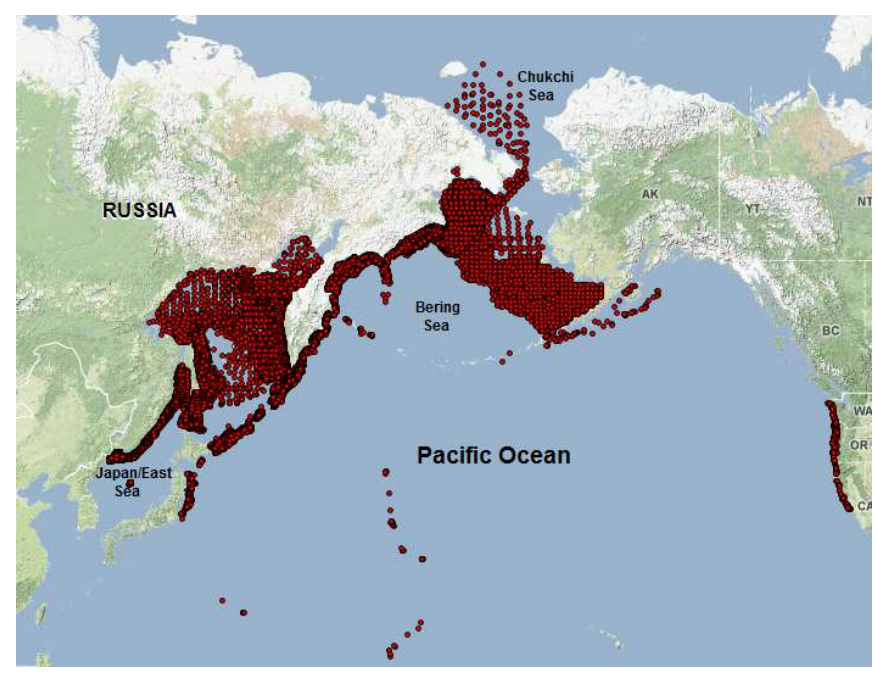

Figure 2. Spatial distribution of trawl stations, information from which is available in the new database

Further, among the selected cruises there were found those, where the invertebrates were not weighted, calculated or taken into account at all, or the data on them were recorded sporadically. The rest were marked as suitable to account not only fish, but also the invertebrates living at the bottom or in the near bottom layer of water. Unfortunately, in many cruises the hydrobiologists were not as accurate as the ichthyologists. Thus, the new DB originally consists of two samples: the whole set of the data imported thereto can be used to study the near-bottom piscifauna and only $2 / 3$ of it - to study all macrofauna or only the invertebrates. In addition, as the rule, ichthyologists filled the trawl cards with the size, number and weight of fish of each species in the catch, while hydrobiologists filled the cards only with one characteristic: either the number of individuals, or their weight (see the example on "Fig. 1"). One had to accept such permanent drawback in the initial data, while the other drawbacks were eliminated to a certain extent.

After developing the original set, significant efforts were spent for the accurate analysis and scrupulous editing of the imported data - all possible tests and correction of mistakes. The algorithms of some of them were published (see e.g. [26]) and implemented on the computer, others cannot be formalized - they require the routine 'manual' or qualified 'mental' work - careful verification of numbers and fragments of texts, knowledge of taxonomy and faunistics, animal areal, their maximum size, etc. Thus:

1) There were found and corrected misprints in the coordinates, dates, depth, speed and other trawling characteristics, as well as records of the size and weight of the aquatic organisms that have arisen, for instance, due to the confusion in the units $-\mathrm{m}$, cm or $\mathrm{mm} ; \mathrm{g}, \mathrm{kg}$, centner or ton.

2) Checklists of animals were corrected taking into account the synonymy and latest innovations in the systematics.

3) The names of species caught very far beyond the well-known for them areas were corrected for the names of species superficially similar to the first ones, but spread in the area of the survey.
4) The records on the catch of those species, which were not well caught by the trawl, were marked as nonmetering, for instance algae, as well as euphausiids, hyperiids, mysids, sagitta, and other representatives of the relatively small plankton found in the webbing net of the trawl.

5) According to the bioassays, there were determined the coefficients of hundreds of regression equations for calculating the individual body weight over the length of the individual. These equations helped to find and correct the records giving the outliers of the average individual weight of fish ( $\mathrm{kg} / \mathrm{ind}$.) due to the erroneous values of number or biomass of species in the catch, and in some cases to calculate the missing values of the number or biomass under the known sizes of individuals. In addition, they helped to clarify the weight boundaries ${ }^{7}$ of size-age classes of some species, for which the differential catchability coefficients have been applied.

The necessity and accuracy of all corrections were verified by the experts on certain taxonomic groups and ecological communities as a whole when compared to the statistical tables and geographical maps, received under the DB before and after the correction.

While developing the new $\mathrm{DB}$, the peculiar problem became the fact that in the selected cruises 90 different trawling systems were applied for the work in benthal "Fig. 3", and none of them has been equipped with the devices measuring the horizontal opening of the trawl.

It is unknown, where the data for the estimates, given in the cruises reports and publications made under the cruises results, came from. In fact, this variable has been replaced by an arbitrary constant. As a rule, it was the same for all trawl stations of one cruise, but it differed several times for the same trawl system in different years (under different heads of the expedition): sometimes - twice, and sometimes 8-10 times. The participants of the cruises usually answered the question of the value and the origin of the very specific values in the following way: "It was said by the fishing master" ${ }^{8}$. It is striking that few people paid attention to the plausibility of this information, though it often had nothing to do with the reality [32].

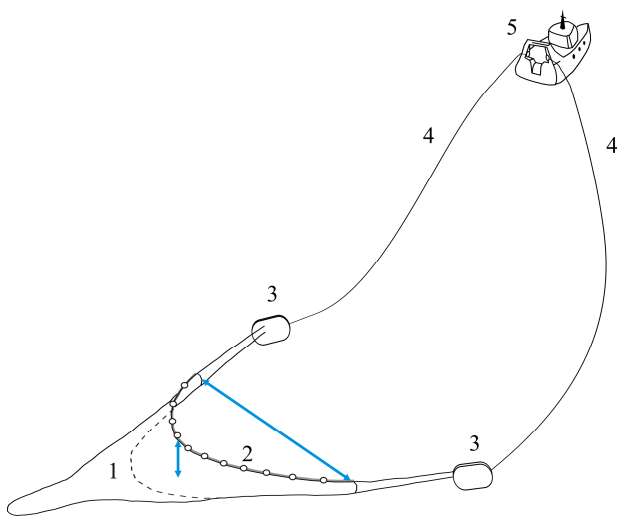

Figure 3. Key elements of the trawl system: 1 - trawl, 2 - net rope (headline), 3 -trawl doors, 4 - towing ropes, 5 - trawler. The dotted line shows the foot rope, arrows - vertical and horizontal opening of the trawl

\footnotetext{
7 Tables with these boundaries, lists of species and relevant coefficients of the catchability are published [27-31] and contained in the DB.

${ }^{8}$ The chief of crew of trawl workers.
} 
There is no doubt that this is the most powerful "factor" of varying the results of many previous studies of fisheries resource base. To avoid serious mistakes because of the huge number of similar incidents in the generalization of material long-term monitoring of bioresources, it was necessary to replace the old records of horizontal opening of the trawl in the new DB with the calculated ones using a united methodology - not the best one, but so far the only one possible. It is based on the generalization of the observations from the submersibles at the work of the trawling systems $[33,34]$, which showed that the horizontal opening of the bottom trawls is about $0.5-0.6$ length of their net rope. Thus, the standard multiplier for the length of the net rope (which is known from the name of the trawl ${ }^{9}$ ) was taken - 0.55 and the expected value of its error of 5\%. For example, the calculated opening of the trawl called DT $27.1 / 25.3$ is equal to $14.91 \pm 1.36 \mathrm{~m}$. In addition, it is necessary to take into account the following two conditions.

Firstly, the fact that the cruise documents, technical descriptions, and even schemes (mounting drawings) may contain the wrong names of the trawls - not according to the state standard [36], and the first number in their name does not correspond to the true length of the net rope specified in the same scheme. To calculate it one should take the actual length from the scheme, but not from the name - if it does not meet state standard. This was done in the evaluation of the horizontal opening of the trawls with the schemes. For the rest, the length of the net rope was defined by their names.

Secondly, the above-described method gives very approximate results only: their error is much higher than mentioned 5\%. However, we do not have the necessary data for the application of more accurate methods (see the review [32]).

At the end of the work on the DB, using the GIS ${ }^{10}$ technology under the map of water area and trawling coordinates there was revealed the hit of each station to one of 48 standard regions of averaging biostatistical information [38], one of 8 bathymetrical zones located between isobaths 0 , 50, 100, 200, 300, 500, 700, 1000 and 2000 m "Fig. 4", as well as one of the plurality of one-degree trapezoids with centers at the points of intersection of the meridians and parallels "Fig. 5". This information was added to the characteristics of the trawl stations to facilitate the standard procedures of statistical and cartographic data processing. After that, a series of last tests was carried out, which consisted of the construction of maps of the distribution of abundant, commercial and indicator species, calculations of the absolute abundance of all species in each bathymetric range of each biostatistical region in different seasons and long-term periods. This work was carried out by successive iterations: after finding the deficiencies by the experts, their source was liquidated, than

\footnotetext{
${ }^{9}$ Russia accepted the standard notation of trawls, which includes the indication of the type of a trawl (DT - bottom, RT - midwater), the length of the net rope without legs in meters, and the perimeter of the wellhead section of the trawl (the front edge of the belly) in embarkation equal to 0.5 [35].

${ }^{10}$ GIS - the common abbreviation of the term "geographic information (or geoinformation) system", which means a computerized system for the collection, validation, integration, storage, analysis and modeling of geographic information related to some part of the earth's surface and used to control it [37].
}

the whole process was repeated again - as long as the comments of the experts were not exhausted, and the DB has come to its present state.

\section{Results and discussion}

As the result, the new DB contains the checked information received for 34 years - since 26.04.1977 to 16.09 .2010 - on 32,699 bottom trawl stations in 224 accurately selected cruises, which materials are suitable both for the applied bioresources, and basic ecologic or biogeographic studies. It includes 459,660 records (rows of the trawl cards), registering the capture of more than 1,400 aquatic species "Table" with the data on their number and/or biomass and sizes.

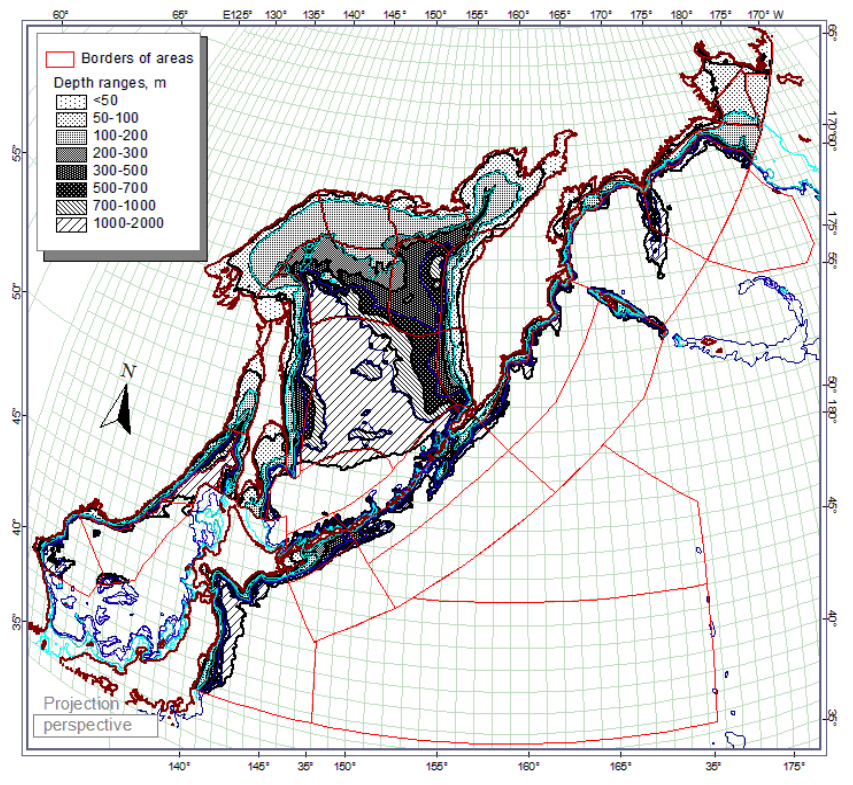

Figure 4. Crossing of 8 bathymetric ranges with 48 standard areas

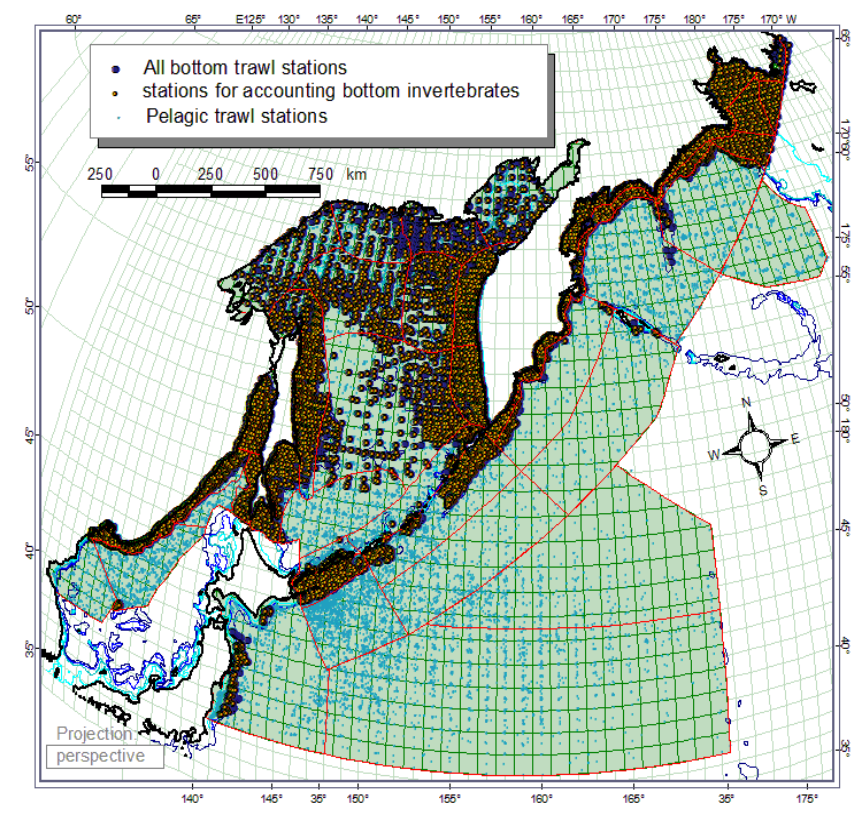

Figure 5. Location of the trawl stations under 48 standard areas of averaging biostatic information and 955 one-degree trapezoids (painted green) in the waters of constant monitoring, where the major part of the raw material base of national fisheries is concentrated 
Table 1. Composition of the studied fauna (number of species)

\begin{tabular}{llll}
\hline $\begin{array}{l}\text { Biotopic } \\
\text { group }\end{array}$ & \multicolumn{1}{c}{$\begin{array}{c}\text { Ecological } \\
\text { form }\end{array}$} & \multicolumn{2}{c}{ Taxonomic groups } \\
\hline & $\begin{array}{l}\text { Nektobenthos } \\
(960)\end{array}$ & $\begin{array}{l}\text { Fish and cyclostomes } \\
\text { Cephalopods (58) }\end{array}$ & $\begin{array}{l}\text { Vertebrates } \\
(833)\end{array}$ \\
& & Prawns and shrimps (69) & \\
& & Gastropods (123) & \\
$\begin{array}{l}\text { Benthal } \\
\text { population } \\
(1448)\end{array}$ & & Bivalves (71) & \\
& Benthos (469) & Crabs (39) & $\begin{array}{l}\text { Invertebrates } \\
(615)\end{array}$ \\
& & Sea urchins (8) & \\
& & Sea cucumbers (14) & \\
& & Others (214) & \\
\hline
\end{tabular}

A part of the DB suitable for accounting all macrofauna, including invertebrate animals, consists of the data from 21,249 stations conducted in 130 cruises.

The DB contains the information of some cruises conducted far from the boundaries of Russia's Exclusive Economic Zone (EEZ) - at the seamounts of the open ocean and near Japan and America (see "Fig. 2"). However, the most valuable are the data from 30,510 bottom trawl stations located in the zone of constant monitoring of the bottom ABR - within the standard regions of averaging information (see "Fig. 5").

The vessels working here could trawl at depths ranging from 5 to $2025 \mathrm{~m}$, so the bottom trawl stations are located not as far from the coast, as pelagic ones, and cover almost three times less water area $-2.2 \mathrm{mln} . \mathrm{km}^{2}$ (bottom area) against 6 $\mathrm{mln} . \mathrm{km}^{2}$ (area of the water surface), regularly inspected by trawl surveys (see "Fig. 5").

According to the Concept of information support of fisheries researches of the Far Eastern seas of Russia [1] the following obvious step after the creation of the DB is to get the information products of a higher level on its basis. They can be called knowledge bases of ABR, because these bases contain not the original raw data, but the results of their statistical and cartographic processing. Since 2002, this work has been carried out in two ways: 1) description of the features of spatial-temporal distribution of animals; 2) assessment of the species composition, occurrence, population density, and total amount of ABR. Earlier, after the introduction of a similar DB with the data on the pelagic population [4], according to the first direction there were prepared GIS containing tens of thousands of digital maps of spatial distribution of aquatic organisms (see, for instance [39-42]) and atlases of quantitative distribution of abundant species of nekton [43-46] were published, which featured approximately 1,000 of selected the most interesting and illustrative maps of each of the basins. In accordance with the second direction there was developed the knowledge base from statistical tables of various characteristics of abundance of all species. Based on its materials, reference books with the tables of number, biomass and species ratio of nekton have been created [47-50], and then of all the pelagic trawl macrofauna [51-53].

There was no need to wait long for the first results of the introduction of the new DB. In 2013, 5 reference books were prepared and submitted for publication [27-31]. These are the new volumes "Fig. 6", somewhat similar to the seven previously published on pelagic of the same region. The included tables contain detailed information on the composition and abundance of all bottoms and near the bottom macrofauna of the surveyed waters. This is the occurrence (\%), number (ind./ $\mathrm{km}^{2}$ ) and biomass $\left(\mathrm{kg} / \mathrm{km}^{2}\right)$ of each species on the average for the entire period of observation, as well as under four seasons (winter, spring, summer, autumn) and four multi-year periods, different by climatic and oceanographic conditions and the status of biological resources - 1977-1990, 1991-1995, 1996-2005 and 2006-2010. Together, they provide an opportunity to assess the population density and gross amount of any benthic ABR of Far Eastern seas and Northwestern Pacific.

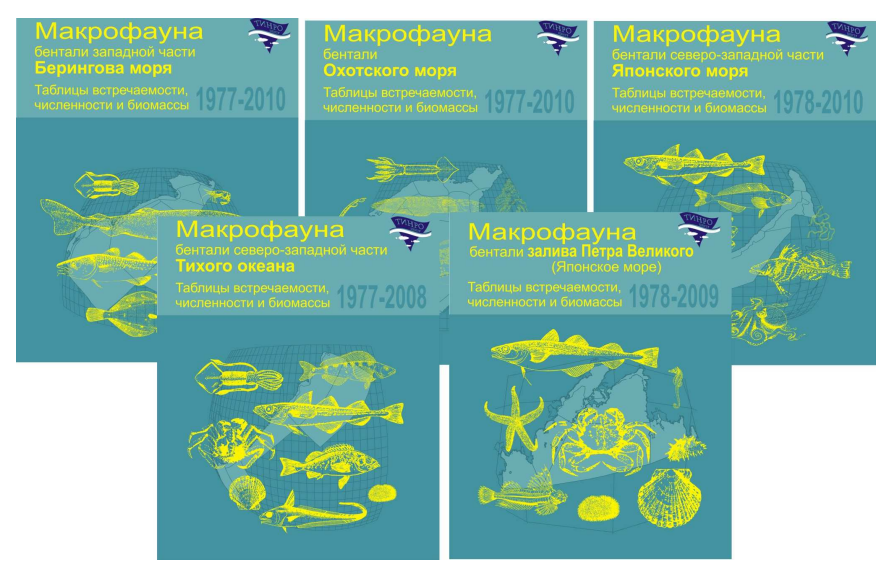

Figure 6. Five tabular reference books, which summarize the data on the occurrence, number and biomass of benthic and nekton-benthic species and groups of the Far Eastern seas and northwestern part of the Pacific Ocean

The next step is to create GIS and, possibly, publish atlases of the bottom ABR. However, it is already clear that this part of the implementation of the information support of fisheries studies of the Far Eastern seas of Russia will come up against significant organizational difficulties. Of course, GIS will be developed in the near future, but the publication of the contained digital maps in the form of atlases will require considerable typographical expenses (initially high prices for color printing are constantly growing). Under the conditions of the annual progressive reduction of funding of TINRO-Center, atlases of the bottom ABR are likely never see the light of day, and the maps prepared for them will be available only for the internal use in the institute.

One can see the potential usefulness of such atlases for scientists, students, fishermen, businessmen and officials in charge of bioresources by the example of several maps made in the process of data validation while developing the DB "Fig. 7-9". We draw attention to the fact that one of the maps in "Fig. 7" shows the distribution of the bottom pollock, which is significantly different from the distribution of this species in the pelagic water layer (see [43-46]), and the other - how sablefish in the years of high population migrates from the North American zone to the Russian part of the Bering Sea, 
and then spreads to the south along the Kamchatka area and through the North Kuril straits enters the Sea of Okhotsk. Map in "Fig. 9" on the left reflects the total biomass of life, ecological environmental capacity, and the intensity of the
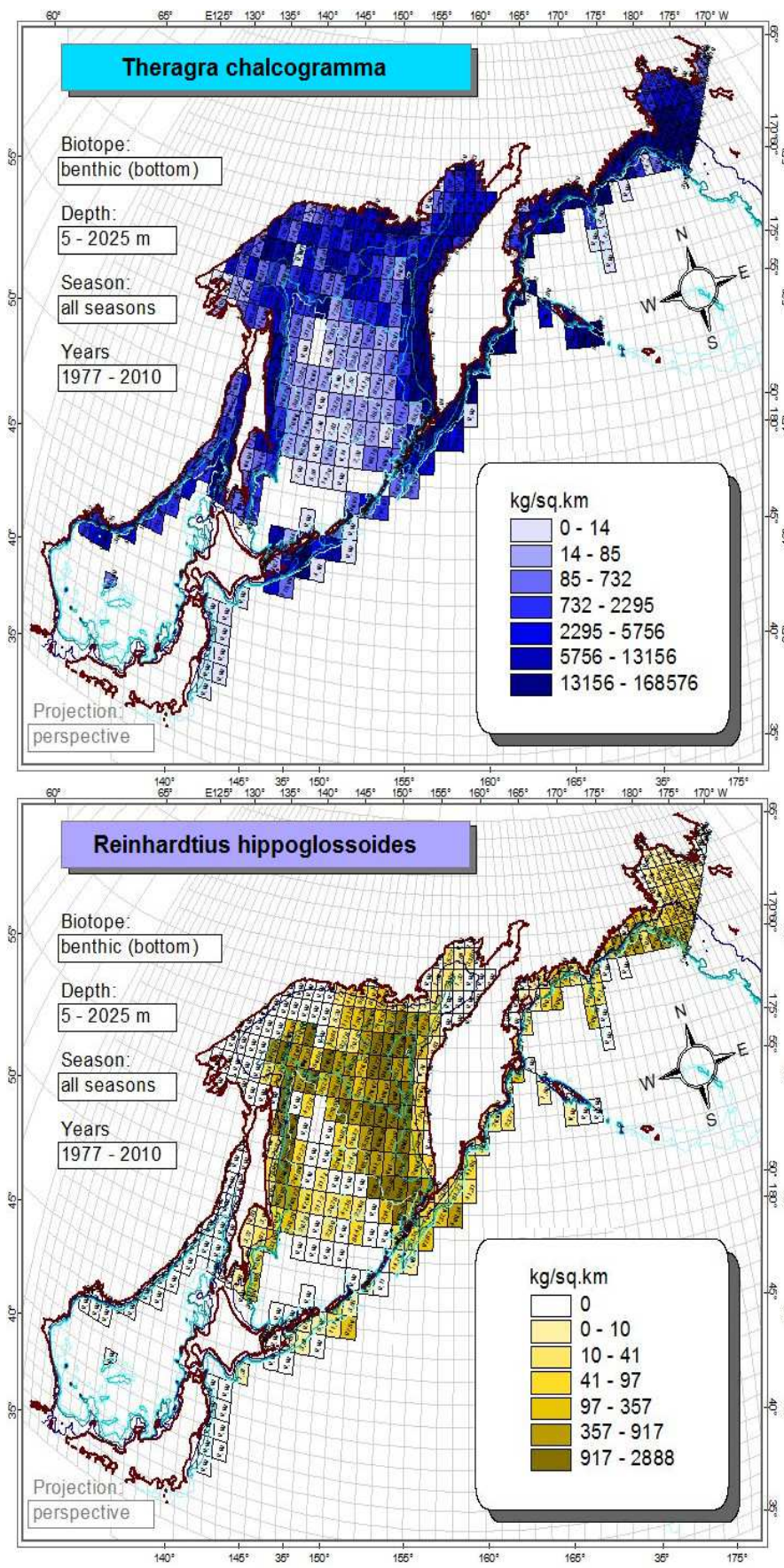

Figure 7. Spatial distribution of the four stocks of valuable fish species (Alaska pollock, Giant grenadier, Greenland halibut, and Blackcod or Sablefish) at the bottom of the waters of long-term monitoring

Unfortunately, a large number of patterns, including unusual and interesting ones, which can be found by the new DB cannot be explored in dynamics. The fact is that the bottom of the northwestern Pacific has been investigated very unequally - both in time and space "Fig. 10". Most of the high-grade materials were collected in the 1980s. Since the beginning of the 1990s, the number of the bottom trawl surveys, the explored spaces and depth ranges nearly over the entire area of the Russian EEZ drastically reduced. In many areas, the work was episodic or even stopped. Dramatic

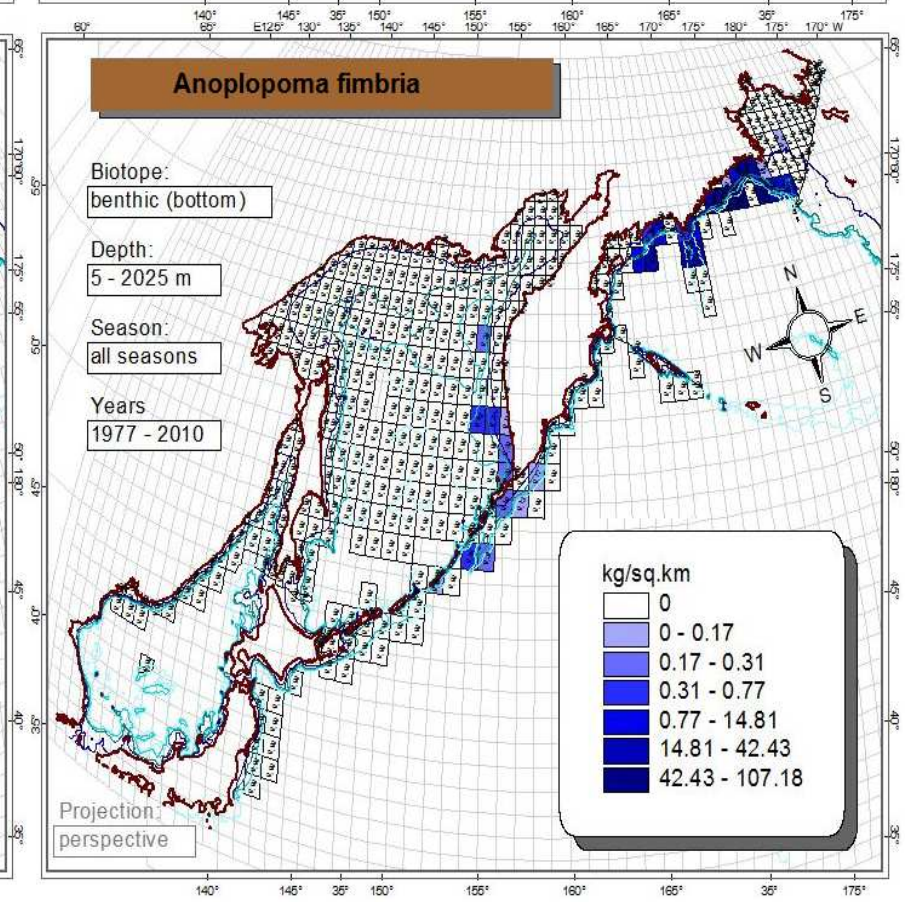

biogeochemical cycling of organic matter in benthal, and the map on the right - the abundance of the bottom macroplankton, which amount in some areas is not less than that near the surface and in the water column.

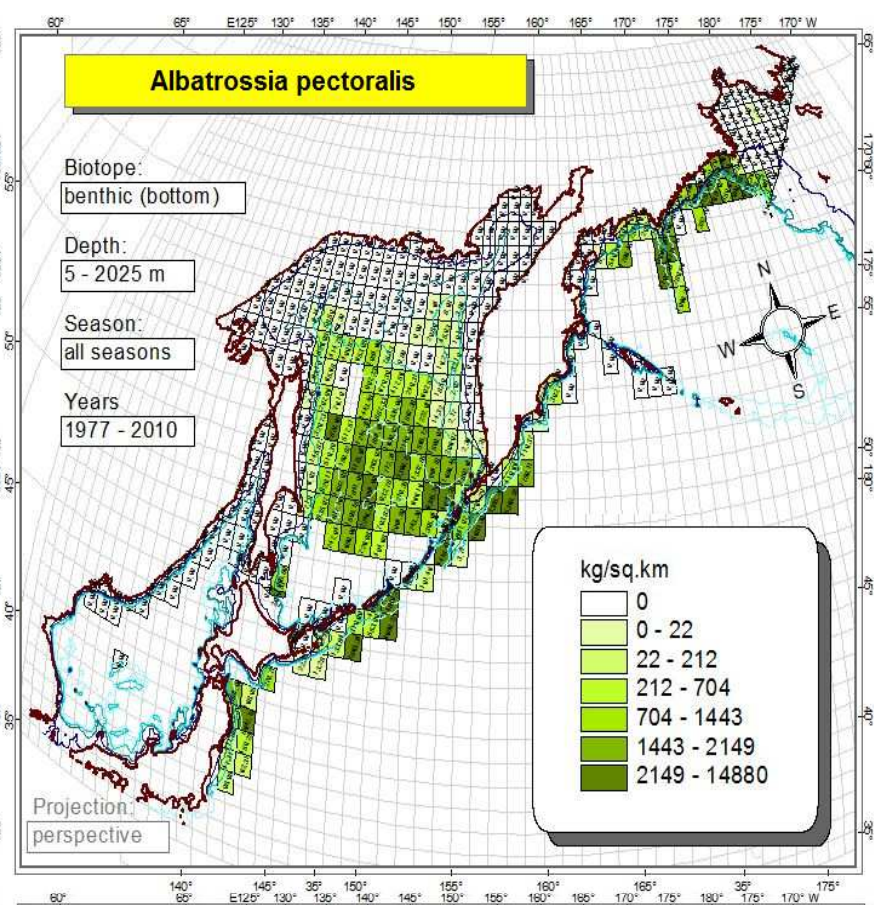


for the first 14 years (1977-1990) there was made more than for the next 20 years: in 1991-1995 the country featured the crisis, in 1996-2005 there was the gradual renewal of work and in 2006-2010 the new crisis happened. There is almost continuous series of observations of the state of the bottom ecosystems and ABR only in Primorye and the western part of

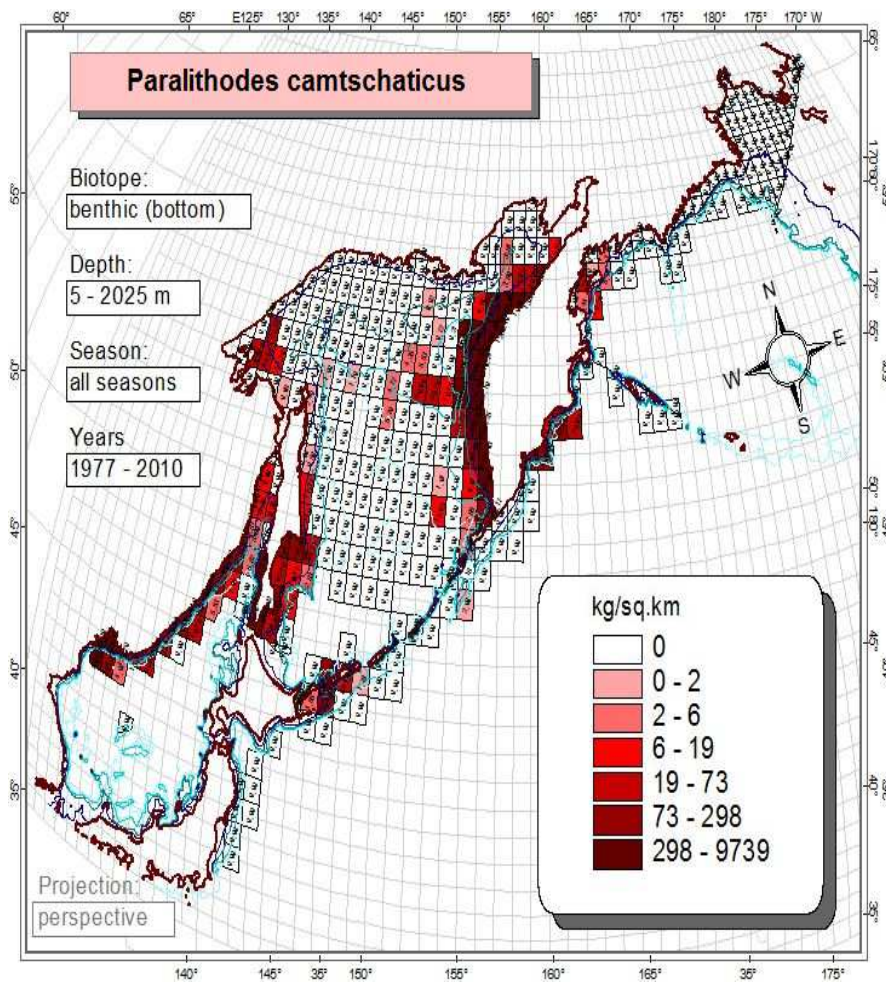

Figure 8. Spatial distribution of stocks of two mass commercial crab species (Red king crab and Opilio tanner crab)

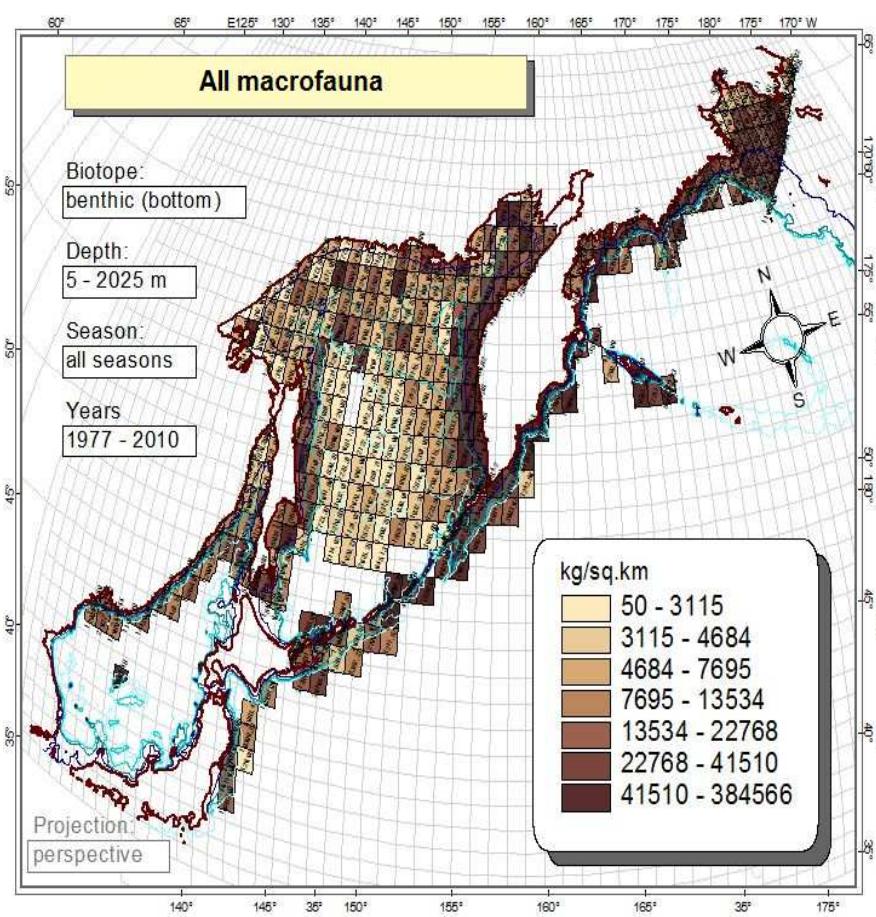

Figure 9. Spatial distribution of entire benthic macrofauna biomass and bottom macroplankton (jellyfish and comb jellies) biomass

Thus, the information from the new DB is useful not only for scientists and fisheries industrialists. It reveals a kind of paradoxical political and economic situation. Just recently, the comprehensive research of aquatic resources, assessment and
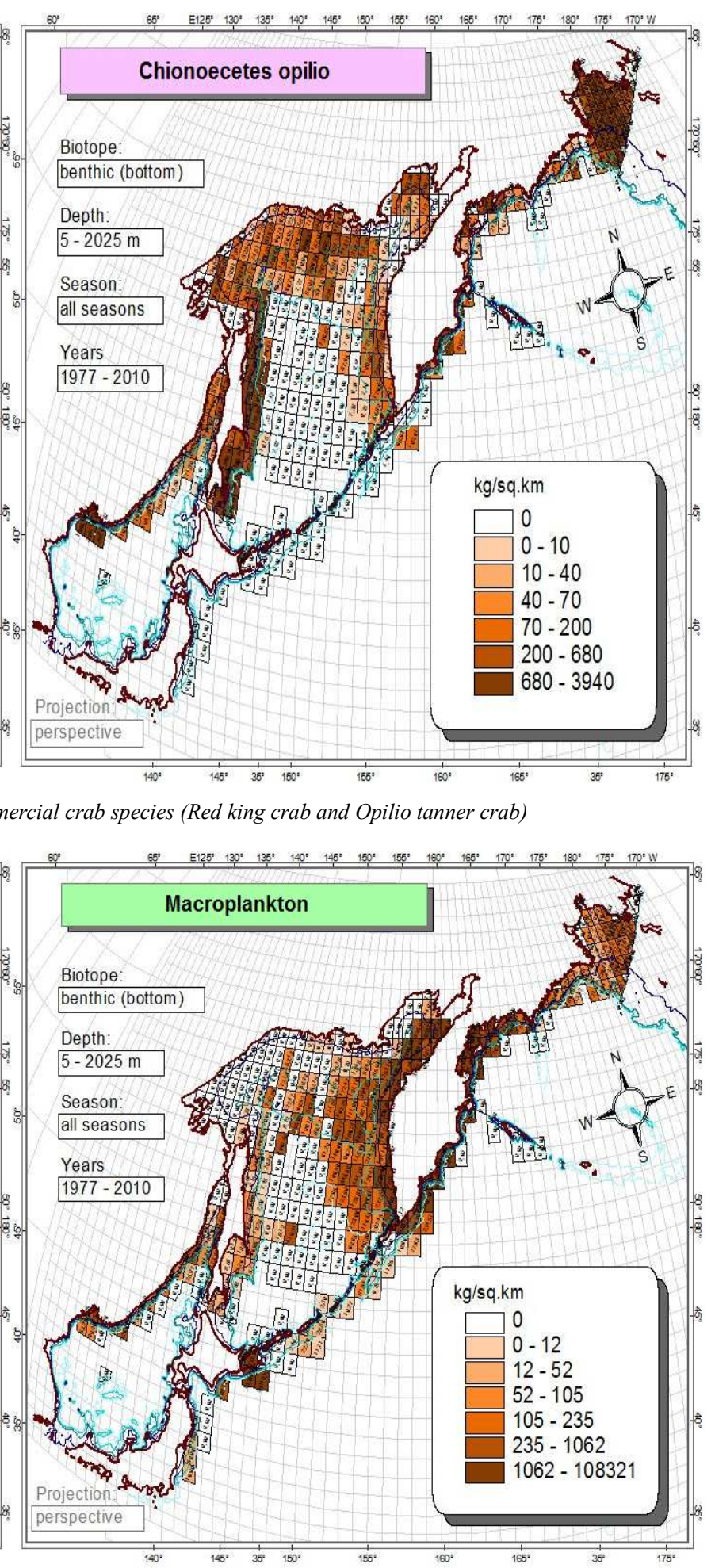

Bering Sea. Therefore, full analysis of the temporal dynamics of the bottom ABR in most parts of the EEZ is impossible. The picture similar to that shown in "Fig. 11", or the worst one, will occur when attempting to trace the interannual dynamics of stocks of demersal fish of any species, and moreover - the bottom invertebrates with less data than about the fish.

monitoring of their state has been included in the most important tasks of scientific research of the fishery science [54-55]. In this century, it is even more important in the context of expanding the exploration of the non-renewable 
bioresources - oil and gas on the sea shelf in the Far East [2]. However, recently the sea expeditions have been actually limited to the cruises providing the short-term forecasts of salmon and pollock fisheries. At the same time there is a loss of a holistic view over the ecosystem and the continuity of the series of the long-term monitoring. You may think that science forced to provide only short-term (routine) interests of fishermen. Perhaps a part of the fishing companies are the opportunists, but the bioresource policy of the state should look to the future. The collected information is now no longer sufficient for the comprehensive ecosystem studies. Besides, we know nothing about what is happening over the last years with the bottom macrofauna in most parts of the Okhotsk Sea, the eastern Kamchatka, eastern Sakhalin and the Kuril Islands, because regular trawl researches have been stopped there long ago $^{11}$.

It was previously noted [2] that "Russia's legging behind in the field of the effective environmental monitoring of waters creates a real threat to the national security of our country" (p. 179). In November 2013, at the meeting of the Russian Security Council president Putin said that the percentage of GDP that Russia spends on environmental measures was in no way comparable with the developed countries. He noticed that environmental security issues had been on the periphery of attention for a long time and asked to accelerate the adoption of state strategies on environmental safety and bring the fundamental and applied researches to a new level. "It is important to understand how the climate changes, what are the prospects for the development of the environmental situation in the country with the forecast horizon for at least 10-15 years. Without such data it is difficult to assess the real threats to environmental security" - said the president [56].

In my opinion, the new database discussed in this paper is a real contribution to the provision of the environmental safety of Russia. The development and constant updating of such DB is especially important in connection with the fact that for a number of reasons the theoretical predictions of tendencies in the dynamics of the marine ecosystems are still difficult. They require constant comprehensive monitoring [2, 11, 17].

Despite the lack of data and the compelled methodical flaws, we have created a unique database. We can confidently assert that no one has better material for the study of benthal biocenotic assemblages, and almost certainly no one will have it in the foreseeable future, because, contrary to the abovementioned requirements of the President to bring the fundamental and applied research to a new level, the scientific fleet of the Far Eastern fisheries research institutions is becoming older, equipment is wearing out, funding is constantly declining, the program of marine expeditions is being phased out ${ }^{12}$. This fact underscores the value of the already existing materials for science and practice. The developed DB, of course, will be a unique basis for future comparisons while monitoring the ecosystems of the northwestern Pacific.

In February 2014, the new database named the Trawling benthic macrofauna of the northwestern Pacific in 1977-2010 was registered in the State Register of the Russian Federation (certificate No. 2014620535). Following the approval of the Regulations on this DB (https://sites.google.com/site/tinrooit/laboratoria-regionalnyjcentr-dannyh) by the Directorate of the Institute, the laboratory of the Regional Data Center ${ }^{13}$ began to perform the TINRO-Center employers' applications for the information contained therein. Representatives of the third-party organizations can get access to this information after the formation of official contracts with the TINRO-Center.

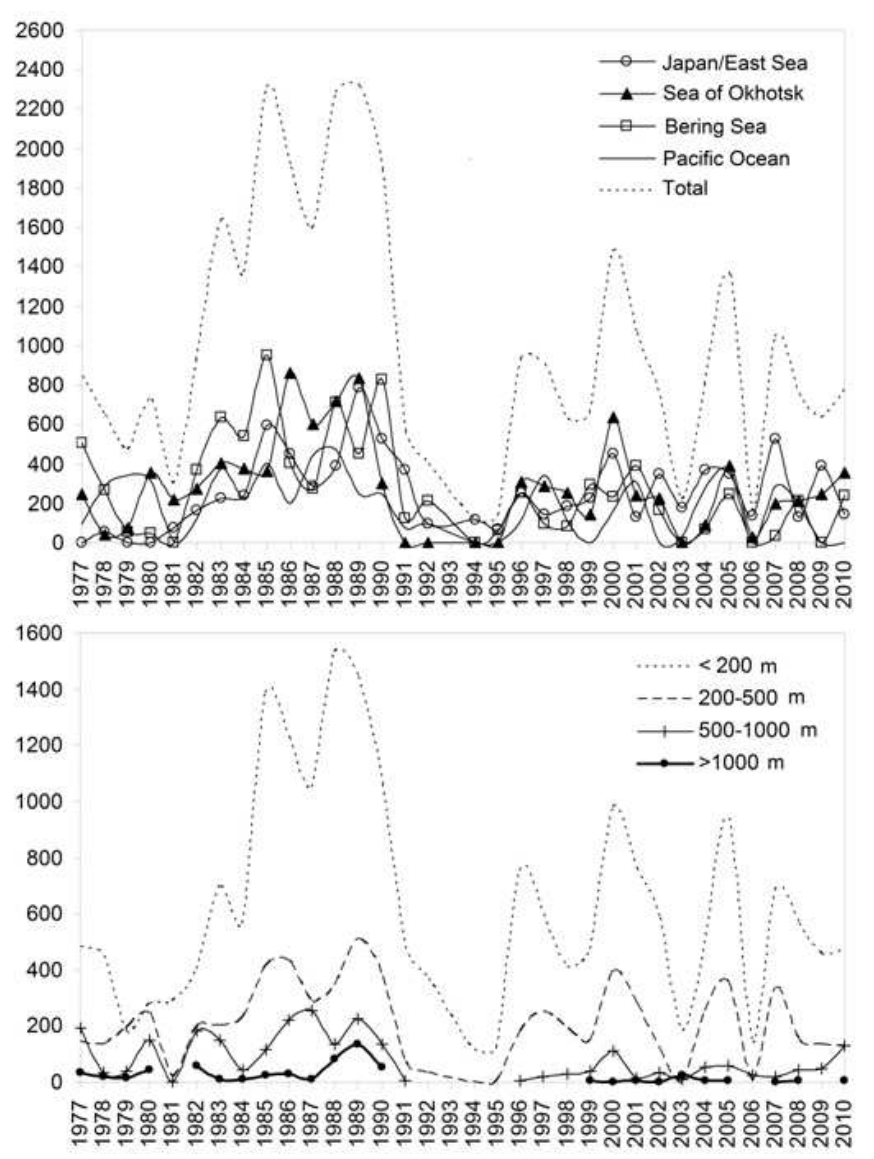

Figure 10. Temporal dynamics of the intensity of surveying the waters in horizontal direction (above) and vertical direction (bottom). Abscissas - years, ordinate - number of the accounted trawl stations

\footnotetext{
${ }^{11}$ Or the information no longer came to TINRO-Center from KamchatNIRO and SakhNIRO contrary to the requirements of the Comprehensive program of fisheries researches in the Far East basin in 2012-2016 (see [3]).

123 research vessels owned by TINRO-Center have already been written off, and another reduction of financing of the institute in 2014 by $10 \%$ compared with the level of 2013 and adjusted for inflation, will lead to a further decline in marine research expeditions $\quad 30 \%$ (http://pollock.ru/press-czentr/news/sovet-adm-obsudil-voprosyi-za konodatelnogo-i-nauchnogo-obespecheniya-ryibolovstva.html).
}

\footnotetext{
${ }^{13}$ A special article [13] describes basic activities of this laboratory.
} 

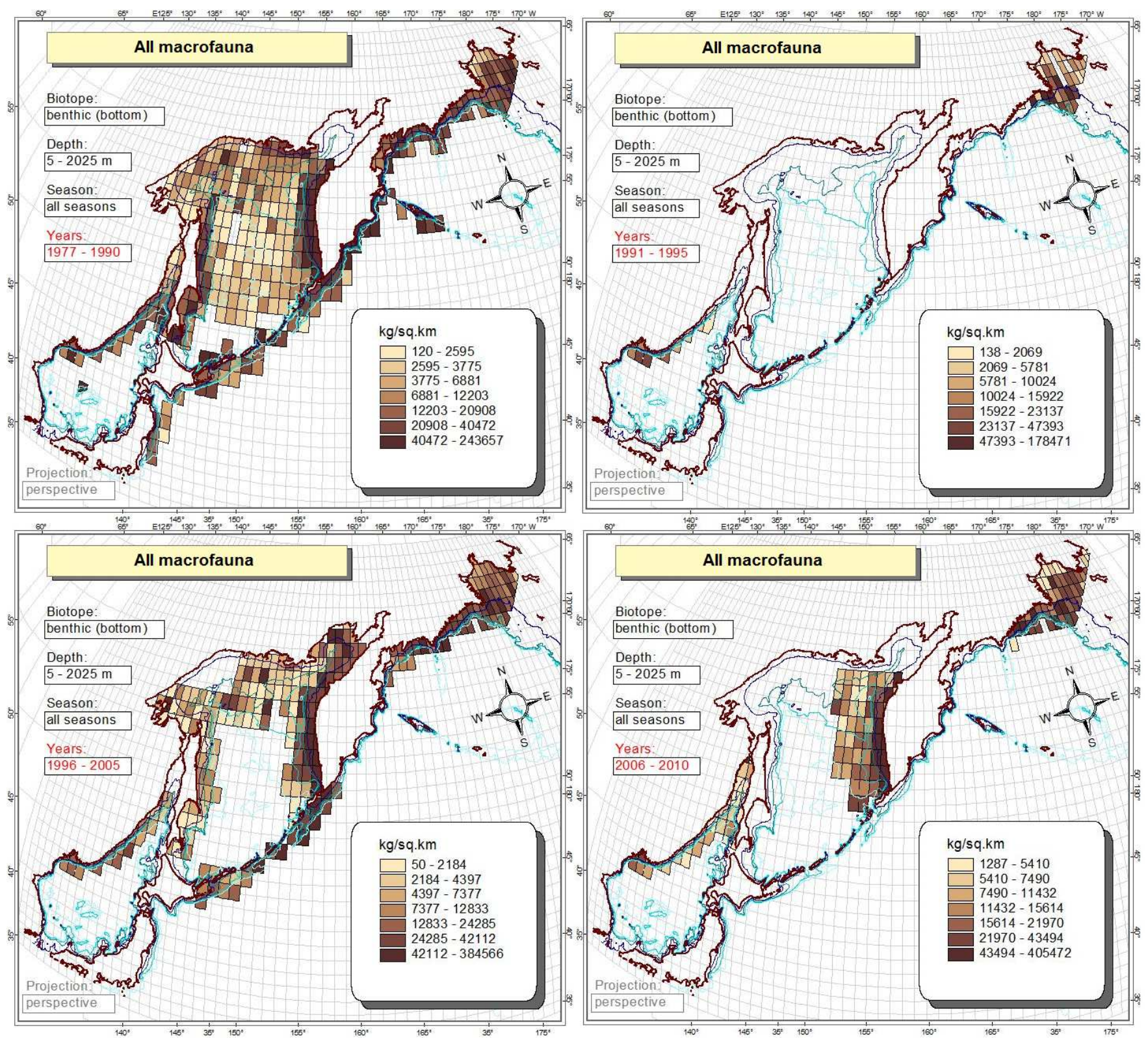

Figure 11. Spatial distribution of entire benthic macrofauna biomass in various multi-year periods, different in climatic and oceanographic conditions and the status of biological resources

\section{References}

[1] I.V. Volvenko, "Information support of fisheries researches of the Far Eastern seas of Russia," in Fisheries researches of the World ocean: Materials of the III International scientific conference, Vladivostok: Dalrybvtuz, 2005, vol. 3, pp. 88-90. (In Russian).

[2] A.V. Adrianov and V.G. Tarasov, "Present-day problems of ecological safety in the offshore zones of the Far East of Russia," in Dynamics of marine ecosystems and present-day problems of preserving the biological potential of the Russian seas, Vladivostok: Dalnauka, 2007, pp. 177-194. (In Russian).

[3] L.N. Bocharov, Comprehensive program of fisheries researches in the Far Eastern basin in 2012-2016, Vadivostok: TINRO-Center, 2012, 149 p. (In Russian).

[4] I.V. Volvenko and V.V. Kulik, ”Updated and extended database of the pelagic trawl surveys in the Far Eastern Seas and North

Pacific Ocean in 1979-2009,” Rus. J. of Mar. Biol., 2011, vol. 37, no. 7, pp. 513-532.

[5] V.P. Shuntov, "Biological Resources of Far Eastern Seas: Prospects of Research and Exploitation," Biologiya Morya (Marine Biology), 1988, no. 3, pp. 3-14. (In Russian).

[6] V.P. Shuntov, V.I. Radchenko, E.P .Dulepova and O.S. Temnykh, "Biological Resources of Far Eastern Russian Economic Zone: the Structure of Pelagic and Benthic Communities, Contemporary Status, and Trends of Long-Term Dynamics,” Izv. TINRO, 1997, vol. 122, pp. 3-15. (In Russian).

[7] V.P. Shuntov, E.P. Dulepova, O.S. Temnykh., A.F. Volkov., S.V. Naydenko., V.I. Chuchukalo and I.V. Volvenko, "State of Biological Resources in Connection with Dynamics of Macroecosystems in the Far Eastern Economic Zone of Russia," in Dynamics of Marine Ecosystems and Contemporary Issues in Conservation of Biological Potential of Russian Seas, Vladivostok: Dalnauka, 2007, pp. 75-176. (In Russian). 
[8] L.N. Bocharov, "The perspective approach to the problem of people supply with fishery products," Izv. TINRO, 2004, vol. 138, pp. 3-18. (In Russian).

[9] L.N. Bocharov, "Development of fishery science in the Far East. Tasks and peculiarities of the present-day stage," in TINRO-85. Results of the decade. 2000-2010, Vadivostok: TINRO-Center, 2010, pp. 3-24. (In Russian).

[10] Planning, staging and supporting of the studies of fish resources of the Far Eastern seas of Russia and northwestern part of the Pacific Ocean / Ed. L.N. Bocharov and I.V. Melnikov, Vladivostok: TINRO-Center, 2005, 231 p. (In Russian).

[11] V.P. Shuntov and O.S. Temnykh, "Illusions and realities of ecosystem approach to study and management of marine and oceanic biological resources," Izv. TINRO, 2013, vol. 173, pp. 3-29. (In Russian).

[12] G.M. Jenkins and D.G. Watts, Spectral analysis and its application, San Francisco: Holden-Day, 1968, 525 p.

[13] I.V. Volvenko, "Regional Data Center (RDC) of FSUE "TINRO-Center": its principal activities and role in the prediction of fisheries resource state," Izv. TINRO, 2014, vol. 176, pp. 3-15. (In Russian).

[14] R.M. May (ed.), Exploitation of marine communities, Berlin ets.: Springer-Verlag, 1984, 367 p.

[15] R.J. Beamish and B.J. Rothschild (eds), The future of fisheries science in North America, Fish and Fisheries, Netherlands: Springer Science+Business Media, 2009, Ser. 31, 736 p.

[16] O.A. Bulatov and B.N. Kotyenyov, "Prospects of the ecosystem management of fishery," in Proc. Conf. All-Russia. scientific. conf. Sustainable use of biological resources of the seas of Russia: Problems and Prospects, Moscow: VNIRO, 2012, pp. 10-11. (In Russian).

[17] V.P. Shuntov, "Untimely notices of the state of fisheries and fisheries science," Bulletin No. 8 of studying the Pacific salmon in the Far East, Vladivostok: TINRO-Center, 2013, pp. 226-235. (In Russian).

[18] L.A. Borets, Bottom ichthyocene of the Russian shelf of the Far Eastern seas: composition, structure, elements and commercial value, Vadivostok: TINRO, 1997, 217 p. (In Russian).

[19] V.P. Shuntov, "The experience of developing a new database of biological resources of the Far Eastern seas," Voprosy Rybolovstva (Fisheries), 2005, vol. 6, no. 6, pp. 172-190. (In Russian).

[20] V.P. Shuntov and I.V. Volvenko, "Atlases of quantitative distribution of nekton in the Far Eastern seas," Far Eastern region - Fisheries, 2005, no. 3, pp. 19-42. (In Russian).

[21] V.P. Shuntov, "Ecosystem studies of biological resources of the Far Eastern seas by TINRO," in TINRO-70, Vladivostok: TINRO, 1995, pp. 20-31. (In Russian).

[22] V.V. Lapko, "Ecosystem study of bioresources in TINRO-Center," in TINRO - 75 years (from TONS to TINRO-Center), Vladivostok: TINRO, 2000, pp. 146-154. (In Russian).

[23] L.N. Bocharov and V.P. Shuntov, "State and tasks of the present-day stage of ecosystem researches of biological resources of the Far Eastern seas of Russia," in Rational environmental management and management of marine bioresources: ecosystem approach, Vadivostok: TINRO-Center, 2003, pp. 3-8. (In Russian).
[24] E.P. Dulepova, "Ecosystem researches of TINRO-Center in the Far Eastern Seas," Izv. TINRO, 2005, vol. 141, pp. 3-29. (In Russian).

[25] V.P. Shuntov, L.N. Bocharov, I.V. Volvenko, O.A. Ivanov, V.V. Sukhanov, N.V. Kolpakov, N.T. Dolganova, E.P. Dulepova and K.M. Gorbatenko, "Ecosystematic Study of Biological Resources in Far Eastern Marine Waters of Russia: Some Results of the Studies in the End of the 20th-beginning of the $21^{\text {st }}$ Century," in TINRO-85. Results of the decade. 2000-2010, Vladivostok: TINRO-Center, 2010, pp. 25-78. (In Russian).

[26] I.V. Volvenko, "Some algorithms of data processing on the abundance and size-weight structure of catches," Izv. TINRO, 1999, vol.126, pp. 177-195. (In Russian).

[27] Benthic macrofauna of the Peter the Great Bay (Japan/East Sea): tables of occurrence, abundance and biomass. 1978-2009 I Ed. V.P.Shuntov and L.N.Bocharov, Vladivostok: TINRO-Center, 2014a, 307 p. (In Russian). (In press).

[28] Benthic macrofauna of the western part of the Bering Sea: tables of occurrence, abundance and biomass. 1977-2010 / Ed. V.P.Shuntov and L.N.Bocharov, Vladivostok: TINRO-Center, 2014b, 803 p. (In Russian). (In press).

[29] Benthic macrofauna of the Sea of Okhotsk: tables of occurrence, abundance and biomass. 1977-2010 / Ed. V.P.Shuntov and L.N.Bocharov, Vladivostok: TINRO-Center, 2014c, 1052 p. (In Russian). (In press).

[30] Benthic macrofauna of the northwestern part of the Pacific Ocean: tables of occurrence, abundance and biomass. 1977-2008 / Ed. V.P.Shuntov and L.N.Bocharov, Vladivostok: TINRO-Center, 2014d, 554 p. (In Russian). (In press).

[31] Benthic macrofauna of the northwestern part of the Japan/East Sea: tables of occurrence, abundance and biomass. 1978-2010 / Ed. V.P.Shuntov and L.N.Bocharov, Vladivostok: TINRO-Center, 2014e, 748 p. (In Russian). (In press).

[32] I.V. Volvenko, "Technical problems of adequate interpretation the results of trawl surveys and ways to solve them," Izv. TINRO, 2013, vol. 172, pp. 282-293. (In Russian).

[33] V.K. Korotkov, A.S. Kuzmina, Trawl, behavior of the fishing object and underwater surveillance, Moscow: Food industry, 1972, 268 p. (In Russian).

[34] V.K. Korotkov, The reaction of fish to the net, the technology of fishing, Kaliningrad: SKEB JSC "MARINPO”, 1998, 398 p. (In Russian).

[35] V.I. Gabryuk, Computer technologies in commercial fishery, Moscow: Kolos, 1995, 544 p. (In Russian).

[36] O.N. Kruchinin, I.V. Volvenko and V.A. Safronov, "Calculation of the bottom trawls geometry by their design parameters," Izv. TINRO, 2012, vol. 170, pp. 241-255. (In Russian).

[37] M.N. DeMers, Fundamentals of geographic information systems, New York : J. Wiley \& Sons, 1997, 486 p.

[38] I.V. Volvenko, "Morphometric characteristic of standard biostatistical regions for the biocenological researches of Russian fishing zone on Far East," Izv. TINRO, 2003c, vol. 132, pp. 27-42. (In Russian).

[39] I.V. Volvenko, "Data Base and GIS technologies in studying nekton of the northwest Pacific: the first results and perspectives," NPAFC Doc. 730, 2003a, 17 p.

[40] I.V. Volvenko, "GIS and Atlas of Salmons spatial-temporal distribution in the Okhotsk Sea," NPAFC Doc. 729, 2003b, 32 p. 
[41] I.V. Volvenko, "GIS for the spatial-temporal dynamics analysis of the Okhotsk Sea nekton," Izv. TINRO, 2004, vol. 137, pp. 144-176. (In Russian).

[42] I.V. Volvenko, "New GIS of the pelagic macrofauna integrative characteristics for the North-West Pacific," Izv. TINRO, 2007, vol. 149, pp. 3-20. (In Russian).

[43] Atlas of quantitative distribution of nekton species in the Okhotsk Sea / Ed. V.P. Shuntov and L.N. Bocharov, Moscow: National Fish Resources, 2003, 1031 p. (In Russian).

[44] Atlas of quantitative distribution of nekton species in the northwestern part of the Japan/East Sea / Ed. V.P. Shuntov and L.N. Bocharov, Moscow: National Fish Resources, 2004, 988 p. (In Russian).

[45] Atlas of quantitative distribution of nekton species in the northwestern part of the Pacific Ocean / Ed. V.P. Shuntov and L.N. Bocharov, Moscow: National Fish Resources, 2005, 1080 p. (In Russian).

[46] Atlas of quantitative distribution of nekton species in the western part of the Bering Sea / Ed. V.P. Shuntov and L.N. Bocharov, Moscow: National Fish Resources, 2006, 1072 p. (In Russian).

[47] Nekton of the Okhotsk Sea. Tables of abundance, biomass and species ratio / Ed. V.P. Shuntov and L.N. Bocharov, Vladivostok: TINRO-Center, 2003, 643 p. (In Russian).

[48] Nekton of the northwestern part of the Japan/East Sea. Tables of abundance, biomass and species ratio / Ed. V.P. Shuntov and L.N. Bocharov, Vladivostok: TINRO-Center, 2004, 225 p. (In Russian).

[49] Nekton of the northwestern part of the Pacific Ocean. Tables of abundance, biomass and species ratio / Ed. V.P. Shuntov and
L.N. Bocharov, Vladivostok: TINRO-Center, 2005, 544 p. (In Russian).

[50] Nekton of the western part of the Bering Sea. Tables of abundance, biomass and species ratio / Ed. V.P. Shuntov and L.N. Bocharov, Vladivostok: TINRO-Center, 2006, 416 p. (In Russian).

[51] Pelagic macrofauna of the western part of the Bering Sea: tables of occurrence, abundance and biomass. 1982-2009 / Ed. V.P. Shuntov and L.N. Bocharov, Vladivostok: TINRO-Center, 2012a, 479 p. (In Russian).

[52] Pelagic macrofauna of the Okhotsk Sea: tables of occurrence, abundance and biomass. 1984-2009 / Ed. V.P. Shuntov and L.N Bocharov, Vladivostok: TINRO-Center, 2012b, 800 p. (In Russian).

[53] Pelagic macrofauna of the northwestern part of the Pacific Ocean: tables of occurrence, abundance and biomass. 1979-2009 / Ed. V.P. Shuntov and L.N. Bocharov, Vladivostok: TINRO-Center, 2012c, 616 p. (In Russian).

[54] A.N. Makoyedov and S.E.Dyagilev, "Optimization of the scientific-research institutes of Goskomrybolovstvo: objective inevitability," Voprosy Rybolovstva (Fisheries), 2002, vol. 3, no. 3 (11), pp. 380-401. (In Russian).

[55] A.N. Makoyedov and O.N. Kozhemyako. Fundamentals of the Russian fisheries policy, Moscow: National Fish Resources, 2007, 480 p. (In Russian).

[56] K. Latukhina, "Natural values. Vladimir Putin instructed to expedite adoption of the strategy of environmental safety," Russian newspaper (Federal issue), 2013, no. 6238 (dated November http://www.rg.ru/printable/2013/11/20/putin-site.html Russian). 